\title{
GH and IGF-I regulate the expression of endothelial nitric oxide synthase (eNOS) in cardiovascular tissues of hypophysectomized female rats
}

\author{
Anna Wickman ${ }^{1}$, Ingibjörg H Jonsdottir ${ }^{1}$, Göran Bergström ${ }^{1}$ and Lars Hedin ${ }^{1,2}$ \\ ${ }^{1}$ Department of Physiology, Göteborg University, PO Box 432, S-405 30 Göteborg, Sweden and ${ }^{2}$ Department of Anatomy and Cell Biology, \\ University of Bergen, Norway \\ (Correspondence should be addressed to Anna Wickman; Email: anna.wickman@fysiologi.gu.se)
}

\begin{abstract}
Objective: This study explored whether short-term replacement therapy with growth hormone (GH) affects blood pressure (BP), heart rate (HR) and endothelial nitric oxide synthase (eNOS) expression in cardiovascular tissues in hypophysectomized (Hx) female rats.

Design and Methods: BP, HR and the expression of eNOS in the aorta, caval vein and heart were studied in $\mathrm{Hx}$ female rats and in $\mathrm{Hx}$ female rats that underwent 7 days treatment with $\mathrm{GH}$ and thyroxine + glucocorticoids $\left(\left[\mathrm{T}_{4}+\mathrm{GC}\right]\right)$. Insulin-like growth factor-I (IGF-I) was included in a second experimental protocol to explore the indirect effect of GH. The expression and localisation of eNOS was analysed by immunoblotting and immunohistochemistry.

Results: Decreased BP (Hx 98 \pm 1, Intact $129 \pm 3 \mathrm{mmHg}, \mathrm{P}<0.05)$, HR (Hx 297 14 , Intact $399 \pm 31$ beats $/ \mathrm{min}, P<0.05)$ and unchanged eNOS expression was demonstrated in Hx compared with intact rats. None of the hormones affected BP, but both GH and IGF-I increased HR compared

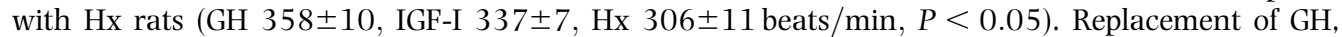
$\mathrm{GH}+\left[\mathrm{T}_{4}+\mathrm{GC}\right]$ and IGF-I resulted in an increased aortic eNOS expression $\left(\mathrm{GH} 161 \pm 24, \mathrm{GH}+\left[\mathrm{T}_{4}+\right.\right.$ GC] $177 \pm 25$, IGF-I $153 \pm 21$, Hx $109 \pm 7 \%, P<0.05$ ), whereas in caval vein only GH $+\left[\mathrm{T}_{4}+\mathrm{GC}\right]$ affected eNOS expression. None of the hormones changed the level of eNOS in the heart. eNOS was localised in the intima layer of the aorta, whereas in the caval vein eNOS was localised in all cell layers.

Conclusions: These findings support the suggested positive role of GH in the regulation of the cardiovascular homeostasis. The observed up-regulation of eNOS, and presumably an increased NO bioavailability, may result in improved endothelial and cardiovascular function.
\end{abstract}

European Journal of Endocrinology 147 523-533

\section{Introduction}

Growth hormone (GH) deficiency or hyposecretion of $\mathrm{GH}$ is associated with an increased risk for cardiovascular mortality (1). These patients demonstrate normal blood pressure, hypotension or hypertension (for review see (2)). They also have endothelial dysfunction (3) and decreased nitric oxide (NO) formation (4). Several studies have shown the clinical benefits of $\mathrm{GH}$ therapy on cardiovascular function in these patients, such as unchanged or decreased systolic and diastolic blood pressure (BP), increased cardiac output (CO), increased heart rate (HR) $(4,5)$, increased NO formation (4) and decreased vascular resistance (5).

Hypophysectomized $(\mathrm{Hx})$ rats demonstrate lowered BP, CO and HR $(6,7)$, as well as endothelial dysfunction (8), decreased heart weight and reduced wall to lumen ratio in the vasculature (9) in comparison to intact rats.
Chronic treatment with $\mathrm{GH}$ results in improved vascular function (10). It has also been demonstrated that substitution with thyroxine $\left(\mathrm{T}_{4}\right)$ and $\mathrm{GH}$ is required for the increase in $\mathrm{BP}$ and for the normal adaptation of the structure of the heart and the vessels in $\mathrm{Hx}$ rats (9).

It has previously been shown that formation of NO can be regulated via the $\mathrm{GH}$-insulin-like growth factor-I (IGF-I) system (4). However, the cellular mechanism for this regulation is unknown. Nitric oxide (NO), formed by endothelial nitric oxide synthase (eNOS), has been shown to play an important role in the physiological regulation of local blood flow and BP $(11,12)$. Although considered to be constitutively expressed, different physiological factors are involved in the regulation of eNOS and NO formation (11).

The clinical consequence of hyposecretion of $\mathrm{GH}$ as well as replacement of $\mathrm{GH}$ for the cardiovascular 
system is well documented, but only a limited number of studies have explored the specific cellular effects of this hormone in vivo. Therefore, the aim of the present study was to investigate the effects of GH on $\mathrm{HR}$ and $\mathrm{BP}$ as well as on the protein content and cellular localisation of eNOS in cardiovascular tissues (caval vein, aorta and heart) after 7 days of administration in $\mathrm{Hx}$ female rats. The second aim was to explore the potential role of IGF-I as a mediator of the action of $\mathrm{GH}$ on eNOS expression.

\section{Materials and methods}

\section{Animals}

Female Wistar rats were obtained from M\&B (Ejby, Denmark). The animals underwent hypophysectomy at the age of 7 weeks (weight approximately $180 \mathrm{~g}$ ) at M\&B. All rats were acclimatised for 1 week before the onset of the experiment. All rats were weighed daily. None of the Hx rats increased their body weight (BW) prior to treatment (experiment (Exp) 1 from 162 \pm 1 to $163 \pm 5 \mathrm{~g}$, Exp 2 from $170 \pm 1$ to $169 \pm 1 \mathrm{~g}$ ), demonstrating complete hypophysectomy (13), while the intact rats (Exp 1) demonstrated an increase in BW of $\sim 13 \%$ (from $190 \pm 2$ to $214 \pm 4 \mathrm{~g}$ ). The rats had free access to standard pellet chow and tap water throughout the study. All experiments were approved by the Regional Animal Ethic Committee, Göteborg University.

\section{Experiment 1}

Hypophysectomised rats were randomised into four experimental groups; $\mathrm{Hx}(n=10$ rats $)$, thyroxine + glucocorticoids $\left(\left[\mathrm{T}_{4}+\mathrm{GC}\right], n=10\right), \mathrm{GH}(n=5)$ and $\mathrm{GH}+\left[\mathrm{T}_{4}+\mathrm{GC}\right](n=10)$. The hormones and vehicle were administered subcutaneously, twice daily for 7 days in a volume of $0.1 \mathrm{ml} / 100 \mathrm{~g}$ rats. Untreated intact rats $(n=10)$ were used as controls. The untreated $\mathrm{Hx}$ and intact rats received vehicle treatment.

\section{Experiment 2}

To explore whether the observed differences in central haemodynamics and aorta in $\operatorname{Exp} 1$ were due to direct action of GH or mediated by IGF-I, IGF-I was included in the second experimental protocol. Three different experimental groups of $\mathrm{Hx}$ rats were used: Hx $(n=6)$, GH $(n=9)$ and IGF-I $(n=9)$. The supplementation of $\left[\mathrm{T}_{4}+\mathrm{GC}\right]$ was not included in Exp 2, since no effects on either aortic eNOS expression in the cardiovascular tissues or on the BP and HR was detected after $\left[\mathrm{T}_{4}+\mathrm{GC}\right]$ treatment in Exp 1. Growth hormone was administered subcutaneously twice daily, whereas IGF-I was delivered subcutaneously for seven days by a constant infusion using Alzet miniosmotic pumps (model 2001, Alza Pharmaceuticals,
Palo Alto, CA, USA). These pumps were inserted into the neck during short-lasting barbiturate anaesthesia of the animals (methohexital sodium, Brietal; Eli-Lilly, Indianapolis, IN, USA) (75 mg/kg body weight, i.p.).

\section{Measurement of plasma IGF-I}

In intact rats $(n=7)$ from Exp 1 and untreated Hx rats $(n=6)$ and Hx rats treated for 7 days with either $\mathrm{GH}$ $(n=7)$ or IGF-I $(n=7)$ from Exp 2, the plasma IGF-I content was analysed by a commercial RIA kit (Mediagnost, Reutlingen, Germany). This RIA kit demonstrates high assay sensitivity as well as uses a highly specific polyclonal antibody that demonstrates about $49 \%$ in cross-reactivity to rat IGF-I (Mr Lindau, Mediagnost, personal communication). This suggests that the endogenous plasma IGF-I levels measured in all animals are underestimated by a factor of two.

\section{Hormones (Exp 1 and 2)}

The following hormones were used: thyroxine (L-thyroxine; Nycomed, Oslo, Norway) $\left(\mathrm{T}_{4}, 10 \mu \mathrm{g} / \mathrm{kg} / \mathrm{day}\right)$ and glucocorticoids (GC, cortisol phosphate; SoluCortef, UpJohn, Puurs, Belgium) (400 $\mu \mathrm{g} / \mathrm{kg} /$ day $)$ (14). Bovine growth hormone (bGH, $1 \mathrm{mg} / \mathrm{kg} /$ day) (14) was generously supplied by American Cyanamide Co. (Princeton, NJ, USA). Insulin-like growth factor-I (IGF-I, $1.25 \mathrm{mg} / \mathrm{kg} /$ day) (15), was a generous gift from Genentech Inc. (San Fransisco, CA, USA).

$\mathrm{T}_{4}$ and GC were diluted in saline, whereas bGH was diluted in $0.05 \mathrm{~mol} / \mathrm{l}$ phosphate buffer ( $\mathrm{pH}$ 8.6) containing $1.6 \%$ glycerol and $0.02 \%$ sodium azide.

\section{Measurements of systolic blood pressure and heart rate (Exp 1)}

Systolic blood pressure (SBP) and HR were measured by tail-cuff plethysmography (Narco BioSystems, Houston, TX, USA) on a randomised selection of rats from three of the groups in Exp 1; intact rats $(n=5)$, Hx rats treated with $\left[\mathrm{T}_{4}+\mathrm{GC}\right](n=5)$ and $\mathrm{Hx}$ rats treated with $\mathrm{GH}+$ $\left[\mathrm{T}_{4}+\mathrm{GC}\right](n=5)$. The measurements were done prior to hormone treatment (at days $-7,-5$ and -3 ), at the onset of treatment (day 0) and during treatment (at days 3, 5 and 7). Some of the SBP and HR data from intact rats and $\mathrm{Hx}$ treated rats with $\left[\mathrm{T}_{4}+\mathrm{GC}\right]$ and $\mathrm{GH}+\left[\mathrm{T}_{4}+\mathrm{GC}\right]$ has been published before (16).

\section{Measurement of conscious mean arterial blood pressure and heart rate (Exp 2)}

Invasive conscious mean arterial blood pressure (MAP) and HR were measured for $30 \mathrm{~min}$ at day $7 \mathrm{in} \mathrm{Hx}(n=$ $5)$, GH-treated $(n=5)$ and IGF-I-treated $(n=5)$ rats. The procedure was performed by a catheterisation (PE-50) of the tail artery during short-lasting anaesthesia (methohexital sodium). The rats were allowed to 
recover for at least $30 \mathrm{~min}$ after the operation before onset of registration.

\section{Dissection and homogenisation of tissues (Exp 1 and 2)}

The rats were killed by decapitation on day 7 of treatment. The inferior caval vein, aorta and heart were quickly excised. The heart was separated into left (including septum, LV) and right ventricles (RV). The tissues were trimmed free of fat and adherent tissues and weighed before being frozen in liquid nitrogen and stored at $-80^{\circ} \mathrm{C}$ until analysis.

Protein was extracted from the aorta, caval vein, LV, RV and liver as previously described (17). The total protein concentration was determined by a commercial protein assay (Bio-Rad, Hercules, CA, USA).

\section{Immunoblotting (Exp 1 and 2)}

The procedure for immunoblotting has previously been described in detail (18). Briefly, $25 \mu \mathrm{g}$ (aorta, caval vein and liver) or $35 \mu \mathrm{g}$ (LV, RV and liver) of total proteins were loaded in each lane on gels $(10 \%$ NuPAGE BisTris gels; Novex, San Diego, CA, USA). The gels were run for $90 \mathrm{~min}$ at constant voltage $(150 \mathrm{~V})$. Molecular weight standards (See Blue; Novex, San Diego, CA, USA) were used on each gel. The proteins were transferred to a polyvinyldifluoride (PVDF) membrane (Amersham, Buckinghamshire, UK). The membranes were then incubated with a mouse monoclonal antibody against eNOS (dilution 1:1000; Transduction Laboratories, Lexington, KY, USA). Immunoreactive protein was visualised by chemiluminescence using an alkaline phosphatase-conjugated secondary antibody (dilution 1:30,000; Sigma, St Louis, MO, USA) and CDP-Star (Tropix, Bredford, MA, USA) as a substrate. The membranes were exposed to ECL film (Amersham) at room temperature for $1-5 \mathrm{~min}$ and the films were subsequently developed. Semi-quantitative measurements of proteins from the immunoblots were made by densitometry (Fluor-S Multimager, Quantity One ver. 4.1.0, Bio-Rad). The optical density (OD) of each band was measured. The lane containing extract of liver was used as a reference on each gel.

\section{Immunohistochemistry (Exp 1)}

Separate animals from the first experimental protocol (two in each treatment group: Intact, $\mathrm{Hx},\left[\mathrm{T}_{4}+\mathrm{GC}\right]$, $\mathrm{GH}$ and $\mathrm{GH}+\left[\mathrm{T}_{4}+\mathrm{GC}\right]$ ) were used for perfusion fixation for immunohistochemistry. Catheterisation of the common carotid artery with outflow from both jugular veins was performed during short-lasting barbiturate anaesthesia (methohexital sodium). The rats were perfused at a pressure of $100 \mathrm{mmHg}$ (Intact) or $80 \mathrm{mmHg}(\mathrm{Hx})$ with phosphate-buffer (PBS) containing $0.58 \mathrm{M} \mathrm{Na}_{2} \mathrm{HPO}_{4}, 0.17 \mathrm{M} \mathrm{NaH}_{2} \mathrm{PO}_{4}$ and $0.68 \mathrm{M} \mathrm{NaCl}$ for $15 \mathrm{~min}$. The perfusion pressure was chosen in relation to the SBP in the respective groups (for details see Results and Fig. 1a). The solution was changed thereafter to $4 \%$ cold $\left(+4{ }^{\circ} \mathrm{C}\right)$ neutral buffered formaldehyde and the rats were perfused for an additional time of $30 \mathrm{~min}$ prior to the excision of the vessel. The aorta and caval vein were further fixated for $60 \mathrm{~min}$ in $4 \%$ formaldehyde and then transferred to $14 \%$ sucrose-PBS at $4{ }^{\circ} \mathrm{C}$ for $24 \mathrm{~h}$. The tissues were embedded in OCT-compound (Sakura Finetek Europe B.V., Zoeterwoude, the Netherlands) and snap frozen in 2-methylbutane chilled on dried ice, and stored at $-80{ }^{\circ} \mathrm{C}$ until analysis (19).

The immunohistochemistry procedure has previously been described by Piontkewitz et al. (19). Briefly, the sections were blocked with 5\% non-fat milk in PBS. This was followed by incubation with antibodies against eNOS (monoclonal antibody, dilution 1:50; Transduction Laboratories, Lexington, KY, USA), von Willenbrand factor (polyclonal antibody, dilution 1:800; Dako A/S, Glostrup, Denmark), or smooth muscle actin (monoclonal antibody, dilution 1:1600; Sigma). After several rinsing steps the sections were incubated with either biotinylated anti-mouse or biotinylated anti-rabbit (dilution 1:200 for both; Vector Laboratories, Burlingame, CA, USA). Rat serum (dilution 1:50) was added in conjunction with the anti-mouse in order to reduce unspecific binding. Thereafter, the sections were developed in streptavidin fluorescein (dilution 1:200; Amersham, Buckinghamshire, UK) and mounted with Moviol/Dabco mounting medium. The following controls for unspecific binding were used: replacement of primary antibody with (1) non-specific anti- $\operatorname{IgG}_{1}$ antibody (dilution 1:800, Dako A/S, Glostrup, Denmark); or (2) 5\% non-fat milk. These controls demonstrated negligible signals (data not shown).

\section{Statistical analysis}

Values are given as means \pm S.E.M. Left ventricular and RV weights (Exp 1), MAP and HR (Exp 2), changes in BW (Exp 1 and 2) and levels of plasma IGF-I were analysed by ANOVA followed by Fisher's LSD as a post hoc test. ANOVA adapted for repeated measures was used to evaluate SBP and HR in Exp 1. The Mann-Whitney rank sum test was used for the analysis of immunoblotting data obtained by densitometric scanning from both experimental protocols. A $P$ value of less than 0.05 was considered significant.

\section{Results}

\section{Experiment 1}

Body weight The BWs of Hx rats and Hx rats receiving $\left[\mathrm{T}_{4}+\mathrm{GC}\right]$ were unchanged throughout the experiment (Hx from $164 \pm 1$ to $161 \pm 1 \mathrm{~g}$; [ $\mathrm{T}_{4}+\mathrm{GC}$ ] from $160 \pm 3$ 
to $157 \pm 4 \mathrm{~g})$. The intact rats showed a slight, but nonsignificant, increase in BW at day 7, compared with day 0 (from $214 \pm 4$ to $218 \pm 3 \mathrm{~g}$ ). Rats supplemented with $\mathrm{GH}$ or $\mathrm{GH}+\left[\mathrm{T}_{4}+\mathrm{GC}\right]$ demonstrated a significant
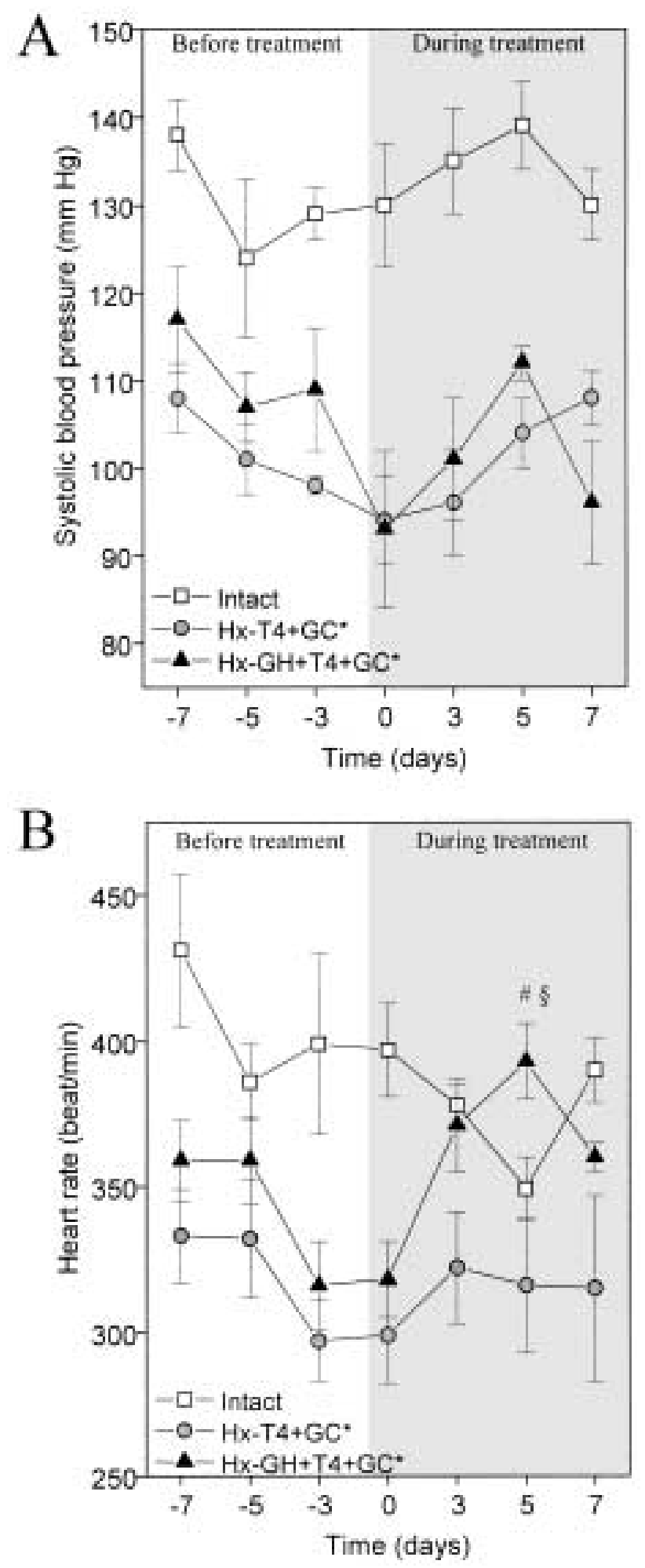

increase in BW (GH from $161 \pm 2$ to $183 \pm 4 \mathrm{~g}, \mathrm{P}<$ $0.05 ; \mathrm{GH}+\left[\mathrm{T}_{4}+\mathrm{GC}\right]$ from $161 \pm 2$ to $187 \pm 2 \mathrm{~g}$, $P<0.05)$.

Systolic blood pressure and heart rate Hypophysectomy per se, resulted in a decrease in both SBP and in HR compared with intact animals $(P<0.05$, Fig. $1 \mathrm{~A}$ and 1B). During replacement (days $0-7$ ), the SBP remained unchanged in all treatment groups (Fig. 1A). Heart rate remained unaltered after replacement with $\left[\mathrm{T}_{4}+\mathrm{GC}\right]$ in $\mathrm{Hx}$ rats (Fig. 1B). However, the animals receiving $\mathrm{GH}+\left[\mathrm{T}_{4}+\mathrm{GC}\right]$ demonstrated an increase in HR from day $3(P<0.05$ compared with day 0 and between $\left[\mathrm{T}_{4}+\mathrm{GC}\right]$ and $\mathrm{GH}+\left[\mathrm{T}_{4}+\mathrm{GC}\right]$ during the treatment period) and reached the same HR level as intact animals (Fig. 1B). The HR remained elevated until the experiment was completed (Fig. 1B).

Left and right ventricular weights Hypophysectomy caused a significant decrease in LV $(P<0.05)$, but not in RV weight, compared with intact rats (Fig. $2 \mathrm{~A}$ and B). After treatment, $\mathrm{LV}$ weight increased in $\left[\mathrm{T}_{4}+\mathrm{GC}\right]$, $\mathrm{GH}$, and $\mathrm{GH}+\left[\mathrm{T}_{4}+\mathrm{GC}\right]$ groups $(P<0.05$ for all vs. Hx, Fig. 2A). There was a small, but significant difference between $\left[\mathrm{T}_{4}+\mathrm{GC}\right]$ and $\mathrm{GH}+\left[\mathrm{T}_{4}+\mathrm{GC}\right]$ in $\mathrm{LV}$ weights $(P<0.05$, Fig. $2 \mathrm{~A})$. None of the treatments had any effect on the RV weight (Fig. 2B).

\section{Expression and cellular localisation of eNOS in aorta, caval vein, RV and $L V$}

Intact and $H x$ rats There were no differences in the eNOS protein expression in the aorta, the caval vein (Figs 3, 4 and $5 \mathrm{a}-\mathrm{d}$ ), the RV (data not shown) or the LV (data not shown) between Hx rats and intact rats.

The expression of eNOS was higher (1.6-fold) in the caval vein compared with the aorta in $\mathrm{Hx}$ animals $(P<0.05$, Figs 3 and 4$)$. There was no difference in eNOS expression between LV and RV in Hx rats (data not shown).

Figure 1 Systolic blood pressure (SBP, A) and heart rate (HR, B) prior to and during treatment. Measurements at $-7,-5$ and -3 days are pretreatment values. Treatment with different hormones (thyroxine + glucocorticoids $\left(\left[\mathrm{T}_{4}+\mathrm{GC}\right]\right)$ and growth hormone (GH)) were started on day 0 . SBP and HR were measured at days 3,5 and 7 . The different groups were hypophysectomized $(\mathrm{Hx})$ treated rats with $\left[\mathrm{T}_{4}+\mathrm{GC}\right](n=5)$ and $\mathrm{GH}+\left[\mathrm{T}_{4}+\mathrm{GC}\right]$ $(n=5)$. Intact rats $(n=5)$ served as controls. Data is expressed as means \pm S.E.M. ANOVA adapted for repeated measures was used for statistical analysis. ${ }^{\star} P<0.05$ between intact control and $\mathrm{Hx}$ rats. " Significant change in $\mathrm{GH}+\left[\mathrm{T}_{4}+\mathrm{GC}\right]$-treated rats compared with day $0(P<0.05) .{ }^{\S} P<0.05$ between $\mathrm{GH}+\left[\mathrm{T}_{4}+\mathrm{GC}\right]$ and $\left[\mathrm{T}_{4}+\mathrm{GC}\right]$ during the treatment periods (day 3,5 and 7 , $P<0.05)$. Some of the SBP and HR data from intact rats and $\mathrm{Hx}$ rats treated with $\left[\mathrm{T}_{4}+\mathrm{GC}\right]$ and $\mathrm{GH}+\left[\mathrm{T}_{4}+\mathrm{GC}\right]$ has been published before (16). 


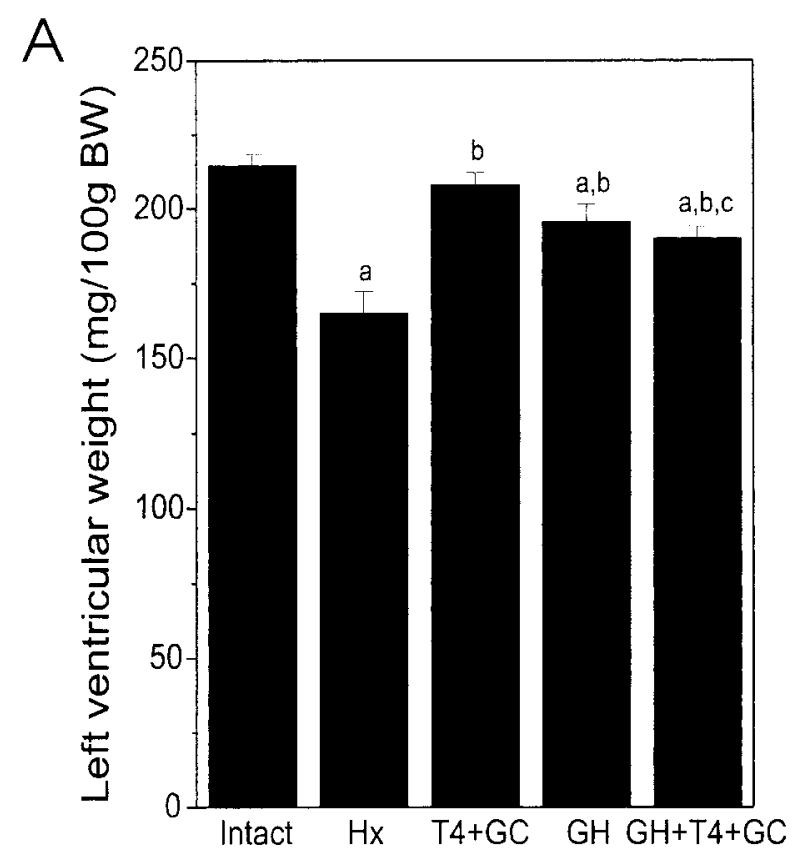

The aorta showed a specific staining for eNOS in the endothelial cells (Fig. 5a and c). Unspecific staining of the elastine components of the media layer was observed in the aorta (Fig. 5a, c, e, g and i). This was also noticed with non-specific $\operatorname{IgG}_{1}$ (data not shown). In the caval vein, the staining included cells localised to the intima, media and adventitia layers (Fig. 5b and $\mathrm{d}$ ).

$\left[T_{4}+G C\right]-, G H$ - and $G H+\left[T_{4}+G C\right]$-treated $H x$ rats The expression of eNOS in aorta, caval vein, LV or RV was not affected by $\left[\mathrm{T}_{4}+\mathrm{GC}\right]$ (Figs. 3 and 4 ). There was an increase of eNOS expression in the aorta after GH supplementation compared with $\mathrm{Hx}$ and $\mathrm{Hx}$ rats treated with $\left[\mathrm{T}_{4}+\mathrm{GC}\right](P<0.05$ for both, Fig. 3). This increase was also observed in the aorta when $\mathrm{GH}$ was combined with $\left[\mathrm{T}_{4}+\mathrm{GC}\right](P<0.05$, Fig. 3$)$. The caval vein of $\mathrm{GH}+\left[\mathrm{T}_{4}+\mathrm{GC}\right]$-treated animals demonstrated a 1.4-fold higher eNOS expression compared with the aorta in the same animals $(P<0.05$, Figs 3 and 4$)$, which was similar a difference as seen in $\mathrm{Hx}$ rats. An increased eNOS expression was shown in the caval vein of $\mathrm{GH}+\left[\mathrm{T}_{4}+\mathrm{GC}\right]$-treated animals compared with $\left[\mathrm{T}_{4}+\mathrm{GC}\right]$ rats $(P<0.05$, Fig. 4$)$. The hormonal

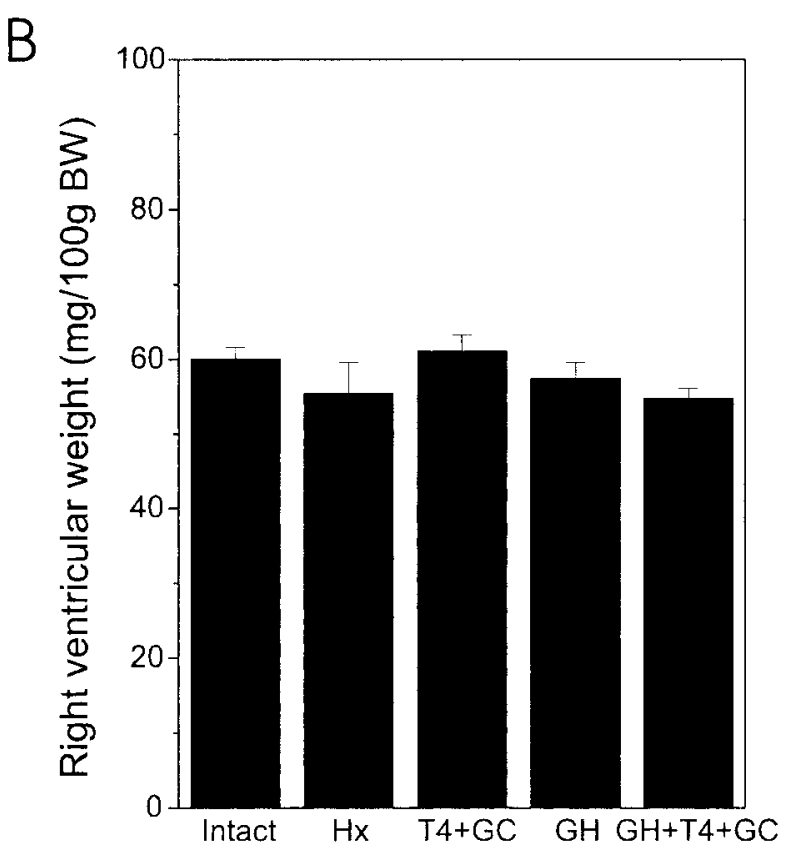

Figure 2 Left $(A)$ and right $(B)$ ventricular weights of intact (controls, $n=10)$, hypophysectomized $(\mathrm{Hx}, n=10)$ and $\mathrm{Hx}$ rats treated thyroxine and glucocorticoids $\left(\left[\mathrm{T}_{4}+\mathrm{GC}\right]\right)(n=10)$, growth hormone $(\mathrm{GH}, n=5)$ or $\mathrm{GH}+\left[\mathrm{T}_{4}+\mathrm{GC}\right](n=10)$ for 7 days. Data is expressed as means \pm S.E.M. Changes in left and right ventricular weight were analysed by ANOVA followed by Fisher's LSD as a post hoc test. ${ }^{a} P<0.05$ between controls and $\mathrm{Hx}$, ${ }^{\mathrm{b}} P<0.05$ between $\mathrm{Hx}$ and the different treatments and ${ }^{\mathrm{c}} P<0.05$ between $\left[\mathrm{T}_{4}+\mathrm{GC}\right]$ and $\mathrm{GH}+\left[\mathrm{T}_{4}+\mathrm{GC}\right]$.

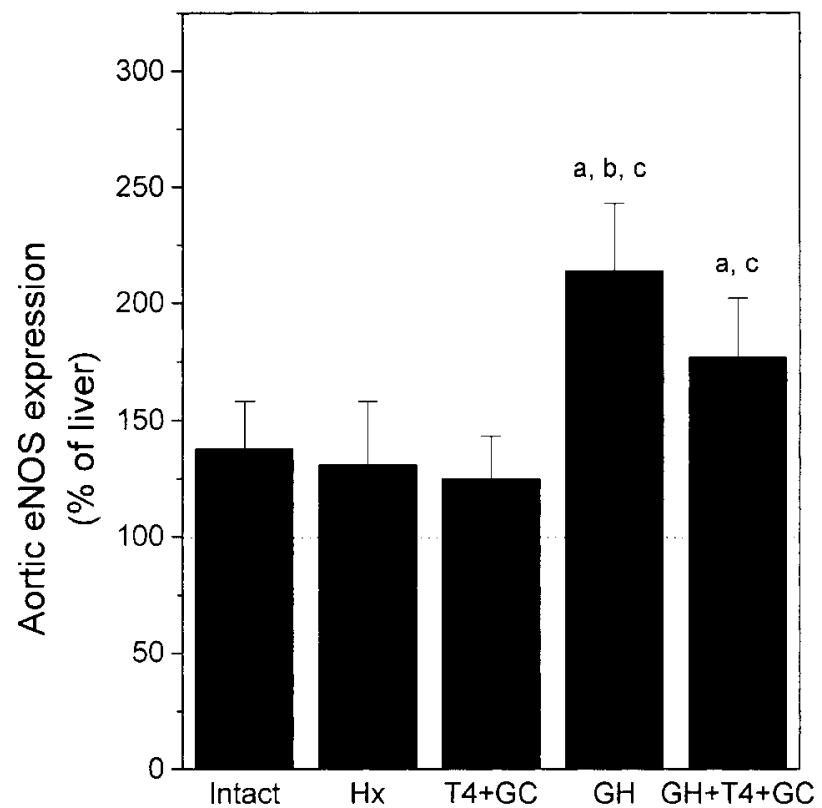

Figure 3 The protein expression of endothelial nitric oxide synthase (eNOS) in the aorta of intact rats (controls, $n=10$ ), hypophysectomized $(\mathrm{Hx}, n=10)$ and $\mathrm{Hx}$ rats after 7 days of treatment with thyroxine and glucocorticoids $\left(\left[\mathrm{T}_{4}+\mathrm{GC}\right]\right)(n=10)$, growth hormone $(\mathrm{GH}, n=5)$, or $\mathrm{GH}+\left[\mathrm{T}_{4}+\mathrm{GC}\right](n=10)$. The values are obtained by densitometric scanning of immunoblots. Data is expressed as means \pm S.E.M. and as a percentage of expression in liver $(=100 \%)$. The same liver sample was used as the standard for each gel. The Mann-Whitney rank sum test was used for statistical analysis. ${ }^{\mathrm{a}} P<0.05$ vs. intact, ${ }^{\mathrm{b}} P<0.05 \mathrm{vs} \mathrm{Hx}$ and ${ }^{\mathrm{C}} P<0.05$ vs $\left[\mathrm{T}_{4}+\mathrm{GC}\right]$. 


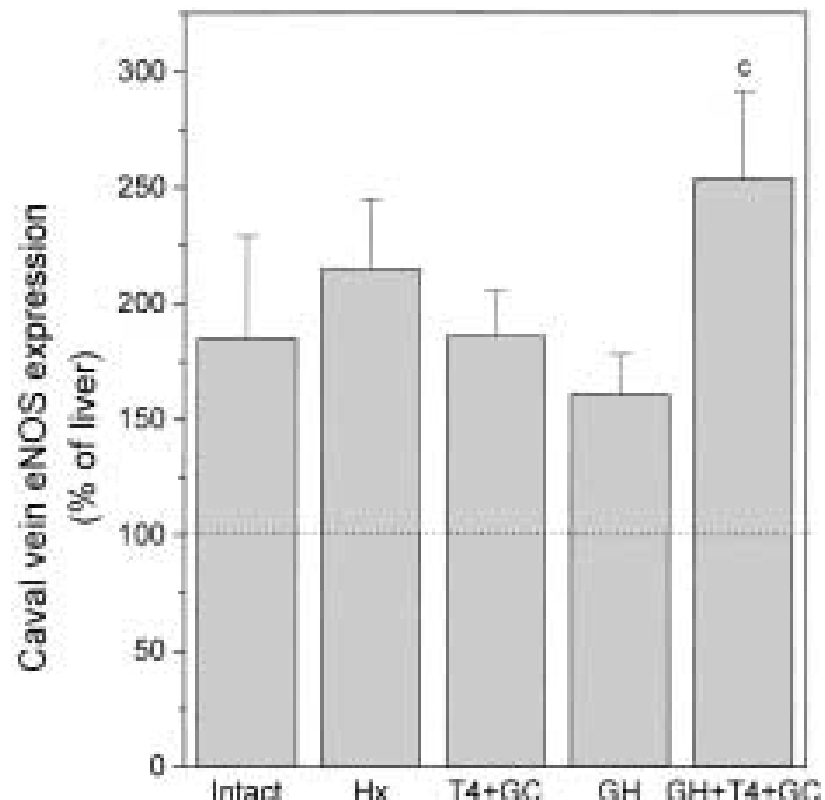

Figure 4 The protein content of endothelial nitric oxide synthase (eNOS) in the caval vein of intact rats (controls, $n=10$ ), hypophysectomized $(\mathrm{Hx}, n=10)$ and $\mathrm{Hx}$ rats after 7 days of treatment with thyroxine and glucocorticoids $\left(\left[\mathrm{T}_{4}+\mathrm{GC}\right]\right)(n=10)$, growth hormone $(\mathrm{GH}, n=5)$, or $\mathrm{GH}+\left[\mathrm{T}_{4}+\mathrm{GC}\right](n=10)$. The values are obtained by densitometric scanning of immunoblots. Data is expressed as means \pm S.E.M. and as a percentage of expression in liver $(=100 \%)$. The same liver sample was used as the standard for each gel. The Mann-Whitney rank sum test was used for statistical analysis. ${ }^{\mathrm{a}} P<0.05$ vs intact, ${ }^{\mathrm{b}} P<0.05$ vs $\mathrm{Hx}$ and ${ }^{\mathrm{c}} P<0.05$ vs $\left[\mathrm{T}_{4}+\mathrm{GC}\right]$. treatment did not affect the protein level of eNOS in the heart (RV or LV) (data not shown).

Immunohistochemistry showed specific eNOS staining in the endothelial cells in the intima layer in the aorta (Fig. 5e, g, and i). In the caval vein, the staining for eNOS was observed in endothelial cells of the intima-, media- and adventitia cell layers (Fig. 5f, h and j). No alteration in the cellular localisation in aorta or caval vein was observed after hormonal treatments compared with controls (intact, $\mathrm{Hx}$ ) (Fig. 5).

The aorta demonstrated unspecific staining for eNOS of the elastine components of the media layer (Fig. 5a, c, e, g and i), which also was observed with non-specific $\mathrm{IgG}_{1}$ (data not shown).

\section{Expression and cellular localisation of von Willen-} brand factor and smooth muscle actin In the aorta, only the endothelial cells in all groups demonstrated staining for von Willenbrand factor (Fig. 6a). In contrast, staining for this factor was present in all layers (intima, media and adventitia) of the caval vein (Fig. 6b). No difference in staining for von Willenbrand factor was observed between the different experimental groups.

The localisation of smooth muscle cells was demonstrated by staining of $\alpha$-smooth muscle actin in both the aorta and the caval vein. All treatment groups showed the same specific staining of $\alpha$-smooth muscle actin in the media of aorta and caval vein (Fig. 6c and d).
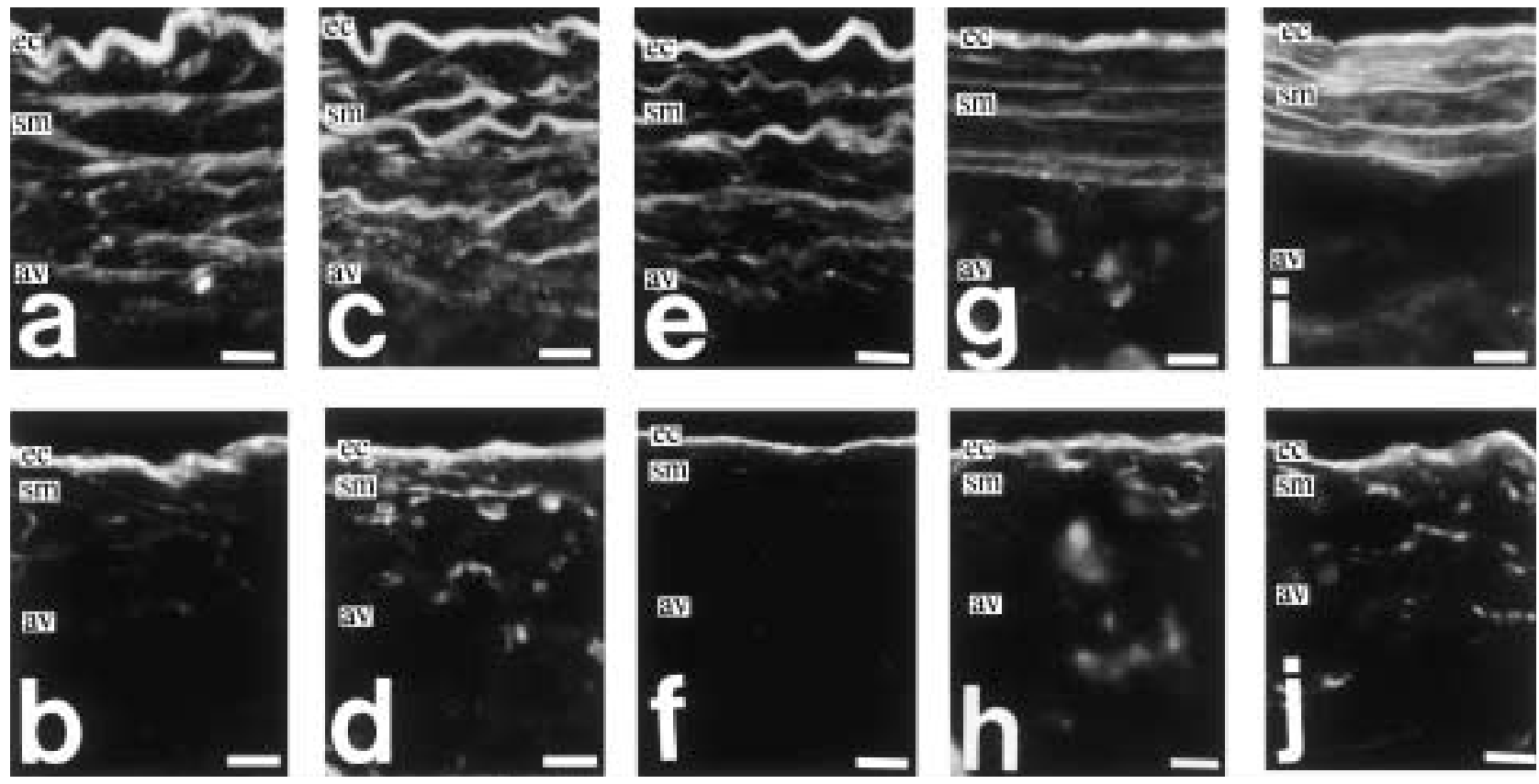

Figure 5 Immunohistochemistry demonstrating the protein expression of endothelial nitric oxide synthase (eNOS) in the aorta (a, c, e, $g$ and i) and the caval vein (b, d, f, h and j) of intact ( $a$ and b), hypophysectomized $(\mathrm{Hx})$ rats (c and d) or $\mathrm{Hx}$ rats treated with thyroxine and glucocorticoids $\left(\left[\mathrm{T}_{4}+\mathrm{GC}\right]\right)$ (e and f), growth hormone $(\mathrm{GH})\left(\mathrm{g}\right.$ and $\mathrm{h}$ ) or $\mathrm{GH}+\left[\mathrm{T}_{4}+\mathrm{GC}\right](\mathrm{i}$ and j). ec, endothelial cells; sm, smooth muscle cells; av, adventitia layer. Scale bars, $50 \mu \mathrm{m}$. 

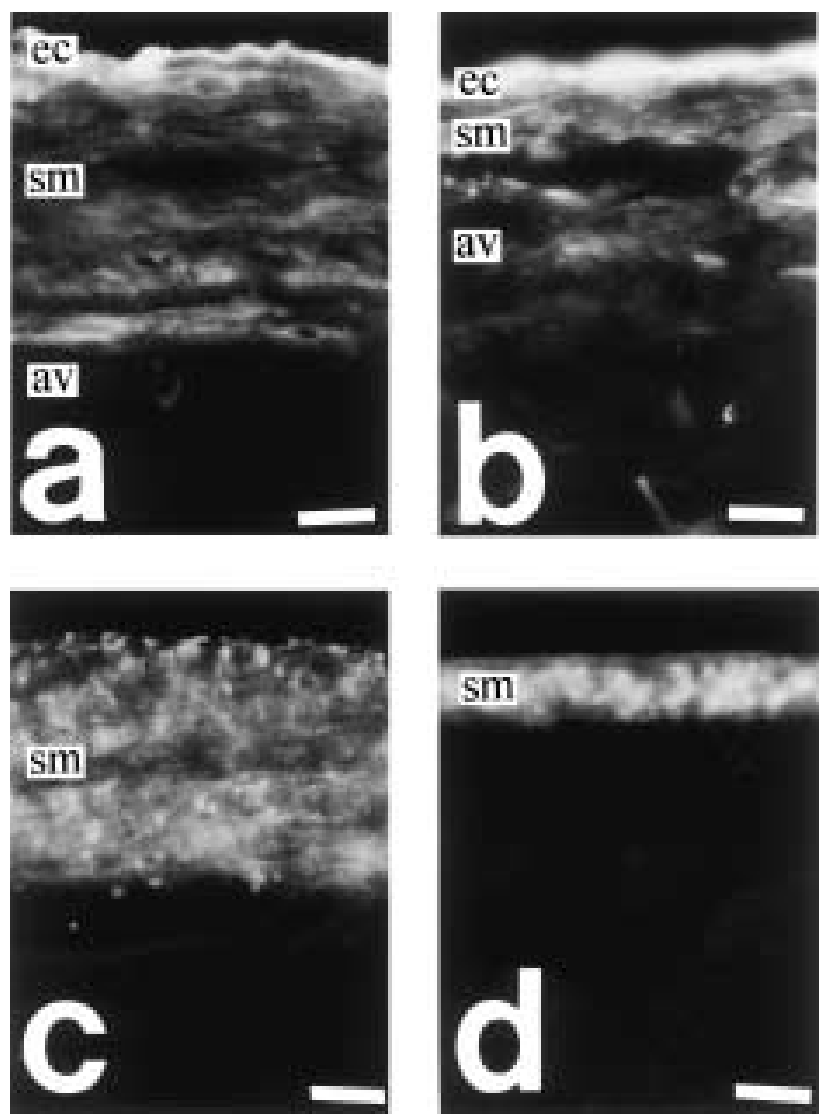

Figure 6 Immunohistochemistry demonstrating the expression of von Willenbrant factor ( $a$ and $b$ ) and smooth muscle actin (c and d) in the aorta (a and c) and the caval vein (b and d) of hypophysectomized (Hx) rats. ec, endothelial cells; sm, smooth muscle cells; av, adventitia layer. Scale bars, $50 \mu \mathrm{m}$.

\section{Experiment 2}

Body weight In the second experimental protocol, the $\mathrm{BW}$ of $\mathrm{Hx}$ rats was unchanged throughout the study (from $173 \pm 2$ to $173 \pm 1 \mathrm{~g}$ ). $\mathrm{GH}$ treatment in $\mathrm{Hx}$ rats demonstrated increased BW from $168 \pm 2$ to $190 \pm 3 \mathrm{~g}$ $(P<0.05)$ and after IGF-I supplementation the BW increased from $161 \pm 2$ to $177 \pm 2 \mathrm{~g}(P<0.05)$.

Table 1 Plasma insulin-like growth factor-I (IGF-I) levels in intact rats, untreated hypophysectomized $(\mathrm{Hx})$ rats and $\mathrm{Hx}$ rats treated with either growth hormone (GH) or IGF-I for 7 days. Values are expressed as means \pm S.E.M.

\begin{tabular}{lcc}
\hline Group & $\mathbf{N}$ & Plasma IGF-I $(\mathrm{ng} / \mathrm{ml})$ \\
\hline Intact & 7 & $491 \pm 55$ \\
Hx & 6 & $43 \pm 6^{*}$ \\
GH & 7 & $273 \pm 18^{\star \#}$ \\
IGF-I & 7 & $319 \pm 26^{\star \#}$
\end{tabular}

ANOVA followed by Fisher's LSD as a post hoc test was used for counting statistically significant changes, ${ }^{*} P<0.05$ vs intact, ${ }^{\#} P<0.05$ vs $\mathrm{Hx}$.
Plasma IGF-I The Hx untreated rats showed a statistically significant decrease in plasma IGF-I compared with intact rats (Table $1, P<0.05$ ). There was a substantial increase of plasma IGF-I in GH- and IGF-I-treated Hx rats compared with untreated $\mathrm{Hx}$ rats (Table 1, $P<0.05)$, whereas both GH- and IGF-I-treated $\mathrm{Hx}$ rats demonstrated lower plasma IGF-I levels compared with intact rats (Table $1, P<0.05$ ). There was no significant difference in plasma IGF-I levels between GHand IGF-I-treated Hx rats (Table 1).

The same pattern of IGF-I levels were found in intact, $\mathrm{Hx}$ and GH groups when compensating for the fact that the IGF-I antibody showed different cross-reactivity to human and rat IGF-I $(P<0.05)$. However, the levels of IGF-I were significantly lower in the IGF-I group compared with the GH group $(P<0.05)$. The recalculated levels were: Intact $981 \pm 110, \mathrm{Hx} 85 \pm 12, \mathrm{GH}$ $547 \pm 35$ and IGF-I $362 \pm 26 \mathrm{ng} / \mathrm{ml}$.

Conscious mean arterial blood pressure and heart rate No change in conscious mean arterial blood pressure (MAP) measurement was observed between the groups (Table 2). Furthermore, the GH-treated $\mathrm{Hx}$ rats showed a $17 \%$ increase in HR compared with untreated Hx rats measured by conscious HR measurement $(P<0.05$, Table 2$)$. An increase in HR was also demonstrated in IGF-I-treated $\mathrm{Hx}$ rats compared with untreated Hx rats $(P<0.05$, Table 2$)$.

eNOS expression in cardiovascular tissues after treatment with GH or IGF-I There was an increase in eNOS protein expression in aorta following GH treatment compared with $\mathrm{Hx}$ rats, as previously shown in Exp $1(P<0.05$, Figs 7 and 8$)$. The group receiving IGF-I demonstrated a similar increase in eNOS expression in the aorta $(P<0.05$ vs Hx, Figs 7 and $8)$ as the group treated with GH. Neither the caval vein nor the heart tissues (LV or RV) showed any changes in eNOS content after GH or IGF-I treatment for 7 days (data not shown). The caval vein contained more eNOS protein than the aorta (Figs 7 and 8), as previously demonstrated in Exp 1.

Table 2 Invasive conscious mean arterial blood pressure (MAP) and heart rate $(\mathrm{HR})$ measurements in hypophysectomized $(\mathrm{Hx})$ rats and $\mathrm{Hx}$ rats treated for 7 days with either growth hormone $(\mathrm{GH})$ or insulin-like growth factor-I (IGF-I). Values are expressed as means \pm S.E.M.

\begin{tabular}{lccc}
\hline Group & $\boldsymbol{n}$ & MAP $(\mathrm{mmHg})$ & HR (beats/min) \\
\hline Hx & 5 & $93 \pm 3$ & $306 \pm 11$ \\
GH & 5 & $94 \pm 2$ & $358 \pm 10^{*}$ \\
IGF-I & 5 & $98 \pm 2$ & $337 \pm 7^{*}$ \\
\hline
\end{tabular}

ANOVA followed by Fisher's LSD as a post hoc test was used for counting statistically significant changes between $\mathrm{Hx}$ and $\mathrm{Hx}$-treated (GH or IGF-I) groups, ${ }^{*} P<0.05$ 


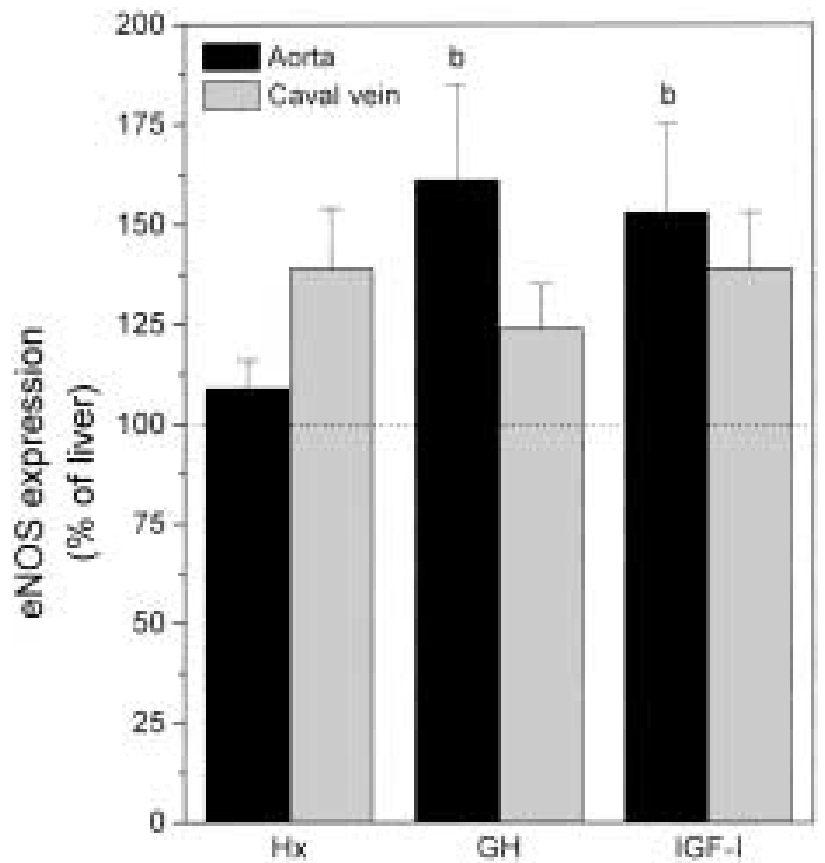

Figure 7 The protein content of endothelial nitric oxide synthase (eNOS) in the aorta and caval vein of hypophysectomised $(\mathrm{Hx})$ $(n=6)$ and $\mathrm{Hx}$ rats after 7 days of treatment with growth hormone $(\mathrm{GH}, n=9)$ or insulin-like growth factor-I (IGF-I, $n=9)$. The values are obtained by densitometric scanning of immunoblots. Data are expressed as means \pm S.E.M. and as a percentage of expression in liver $(=100 \%)$. The same liver sample was used as the standard for each gel. The Mann-Whitney rank sum test was used for statistical analysis. ${ }^{b} P<0.05$ vs Hx.

\section{Discussion}

The major findings in the present study were that hypophysectomy resulted in decreased BP and HR. Neither replacement with $\left[\mathrm{T}_{4}+\mathrm{GC}\right]$ nor $\mathrm{GH}$ or IGF-I restored BP, but both GH and IGF-I replacement increased HR. This study also demonstrates that GH treatment alone elicits a stimulatory effect on eNOS expression in the aorta in vivo in female $\mathrm{Hx}$ rats, but not in the caval vein or in the heart, whereas, GH in combination with $\left[\mathrm{T}_{4}+\mathrm{GC}\right]$ results in an increased eNOS expression in both vessels. Administration of IGF-I resulted in

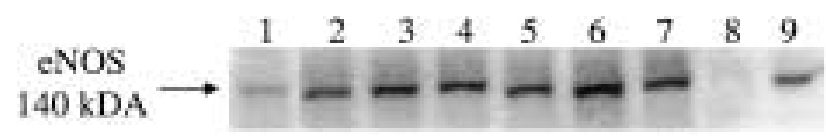

Figure 8 Immunoblotting demonstrated endothelial nitric oxide synthse (eNOS) expression in aorta and caval vein in hypophysectomized $(\mathrm{Hx})$ female rats and in $\mathrm{Hx}$ rats treated with either growth hormone $(\mathrm{GH})$ or insulin-like growth factor-I (IGF-I) for 7 days. Lane 1, endothelial cells (positive controls); Lane 2, aorta from untreated $\mathrm{Hx}$ rat; Lane 3, aorta from $\mathrm{GH}$-treated $\mathrm{Hx}$ rat; Lane 4, aorta from IGF-I-treated $\mathrm{Hx}$ rat; Lane 5, caval vein from untreated $\mathrm{Hx}$ rat; Lane 6, caval vein from $\mathrm{GH}$-treated $\mathrm{Hx}$ rat; Lane 7, caval vein from IGF-I-treated Hx rat; Lane 8, ovcar cells (negative controls); Lane 9, liver from intact rats (positive controls). increased aortic eNOS expression, but had no effect on the eNOS expression in the other studied tissues. In addition, the distribution of eNOS differed between the two vessel types. In the aorta, the expression of eNOS was localised to the endothelial cells of the intima, whereas the caval vein expressed eNOS in all cell layers (intima, media and adventita). Our results suggest that the effect on eNOS expression in the arteries (aorta) could partly be mediated by IGF-I and/or by a direct effect of $\mathrm{GH}$ on the vascular cells. In the veins another indirect effect of GH may mediate this increased eNOS expression.

\section{Cardiovascular function}

The present study demonstrated decreased BP and HR after hypophysectomy. These results are in accordance with those of László et al. (6), Shen et al. (7) and Folkow et al. (9). A reduced structural adaptation of the left ventricle (present study and (9)) as well as lower CO $(6,7)$ together with loss of vascular structure, e.g. reduced synthesis of collagen (20) and reduced wall/lumen ratio in the resistance vessels (9), may explain the reduction of $\mathrm{BP}$ in $\mathrm{Hx}$ rats. After 7 days of supplementation with $\left[\mathrm{T}_{4}+\mathrm{GC}\right], \mathrm{GH}$ or IGF-I the LV weight increased up to the levels of intact rats, although the BP was still reduced compared with intact rats in all hormonal treatment groups. Folkow et al. (9) demonstrated that 6 weeks of $\mathrm{GH}+\mathrm{T}_{4}$ supplementation to $\mathrm{Hx}$ rats restored the blood pressure, LV weight and the vascular structure to those of intact rats. Our study may suggest that 1 week of hormonal replacement seems to be enough to create normal LV weight in these rats, but it seems that longer replacement therapy is needed to create a normalisation of the vascular structure.

Both in the present study and in studies involving humans (4), an increase in HR has been demonstrated after supplementation with either GH or IGF-I. This finding (increased $\mathrm{HR}$ and unaltered BP) can be explained by: (i) a stimulatory effect of GH and IGF-I on the heart followed by dilatory response in the resistance vessels, or (ii) a primary effect (dilatation of vessels) of GH and IGF-I with a reflexogenic increase in HR to maintain BP. Our results support the second explanation since the major effect of GH and IGF-I on eNOS protein expression was observed in the aorta, leaving the level of eNOS protein in the heart unaffected. An increase in eNOS expression may result in an increased NO bioavailability, causing a decreased total peripheral resistance (TPR). A decreased TPR after $\mathrm{GH}$ supplementation to a GH-deficient patient has previously been reported (5). Thus, this may suggest that an increased eNOS expression in the arteries together with increased NO bioavailability can cause the reduced TPR in the GH-supplemented GH-deficient patients. 


\section{eNOS expression and localisation}

Interestingly, in the present study, the level of eNOS protein was unaltered by hypophysectomy in the aorta, caval vein and the heart. Growth hormone deficient patients demonstrate a decreased NO formation in the urine and plasma compared with control patients (4). One explanation for the unaffected vascular eNOS expression in the $\mathrm{Hx}$ rats could be the time frame. Our untreated Hx rats were studied 3 weeks after hypophysectomy, whereas the majority of all patients studied have a chronic (years) deficiency of GH. In addition, specific vascular eNOS expression has not been studied in GH-deficient patients. A second explanation could be that the production of NO is not restricted to the eNOS isoform but also involves the two other isoforms of NOS, neuronal and inducible (21). Moreover, it is also possible that the effect of eNOS might not be limited to the transcriptional/post-translational level. Several factors have been demonstrated to influence the enzymatic activity of eNOS (22). Thus, further studies are needed to elucidate the effect of short- and long-term hypophysectomy, the enzymatic regulation of eNOS as well as to ascertain if the other two isoforms of NOS are involved.

The present study demonstrates that treatment with both $\mathrm{GH}$ and $\mathrm{GH}$ together with $\left[\mathrm{T}_{4}+\mathrm{GC}\right]$ resulted in an increased eNOS expression in the aorta. Administration of $\left[\mathrm{T}_{4}+\mathrm{GC}\right]$ did not change the eNOS expression in any of the studied tissues. This suggests that GH ellicits a stimulatory effect on aortic eNOS expression in female $\mathrm{Hx}$ rats. $\mathrm{GH}$ is known to mediate its effects either directly on the target cells or indirectly via IGF-I. To explore whether the effect of $\mathrm{GH}$ on aortic eNOS expression was mediated via GH directly or via IGF-I a second experimental protocol was used in which $\mathrm{Hx}$ rats were treated with either GH or IGF-I. Our results showed a marked increase in eNOS expression in the aorta after 7 days of treatment with IGF-I, similar to the effect of GH. No changes of eNOS expression could be detected in either the caval vein or in the cardiac tissues after IGF-I treatment. This suggests that the increased aortic eNOS expression can be due to a direct effect of GH in this vessel or an indirect effect mediated by IGF-I, or a combined effect of these two hormones. The levels of serum IGF-I in GH- and IGF-I-supplemented Hx rats were similar, although lower compared with intact rats. These results demonstrate that the doses of GH and IGF-I used in the present study are within the physiological range. However, the endogenous plasma IGF-I levels measured in the present study are underestimated by a factor of two due to the use of a human IGF-I antibody (for more detailed information see Materials and methods).

Several in vitro and in vivo studies have shown that IGF-I can activate NO production both in endothelial cells and smooth muscle cells, resulting in vasodilation and an increased blood flow (23, 24). Böger et al. demonstrated an increased NO formation, both in plasma and urine, after chronic GH treatment of GHdeficient patients (4). They suggested that the increase in NO formation was mediated by IGF-I (4). Taken together, our results suggest that the effects on eNOS expression seen in the aorta could be partly mediated by IGF-I and/or by a direct effect of GH on the target cells. We acknowledge that further studies are needed to elucidate if the effect on eNOS expression in the endothelial cells in the aorta is a direct effect mediated by $\mathrm{GH}$ and/or IGF-I.

It is also possible that the increased HR (or presumed increased sympathetic activity) seen after both GH and IGF-I treatment could indirectly stimulate eNOS expression in the aorta. An effect of sympathetic activation is less likely since $\beta$-receptor blockade appears to stimulate eNOS expression in vitro (25). However, it may be suggested that the increased frequency of cyclic stretching of the aorta, mechanically induced by the increased HR could be responsible for the increased eNOS expression seen in the aorta. This is supported by an ex vivo experiments by Gan et al. (26). Further experiments are needed to elucidate this hypothesis.

Another indirect effect of $\mathrm{GH}$ is the enhancement of the conversion of $\mathrm{T}_{4}$ to tri-iodothyronine $\left(\mathrm{T}_{3}\right)$ via upregulation of deiodinase enzyme (27). The combined treatment of $\mathrm{GH}$ and $[\mathrm{T} 4+\mathrm{GC}]$ used in the present study may therefore result in increased plasma levels of $\mathrm{T}_{3}$ (28). In addition $\mathrm{T}_{3}$ has been shown to induce eNOS expression in the liver of rats (29). Thus, an increased $\mathrm{T}_{3}$ plasma level may explain the increased eNOS expression in the caval vein after combined treatment with $\mathrm{GH}$ and $\left[\mathrm{T}_{4}+\mathrm{GC}\right]$ but not after $\mathrm{GH}$ alone or after IGF-I. However this possibly confounding effect of $\mathrm{T}_{3}$ seems to be limited to the caval vein, since changes in aortic eNOS expression was also observed both after $\mathrm{GH}$ treatment alone and after $\mathrm{GH}+\left[\mathrm{T}_{4}+\mathrm{GC}\right]$ treatment.

The immunohistochemical localisation of eNOS showed a specific staining in the aortic endothelial cells of the intima layer in all groups. In contrast, the caval vein demonstrated staining for eNOS in intima, media and adventitia layers. Since von Willenbrand factor has been shown to be specific for endothelial cells, the co-localisation of eNOS and von Willenbrand factor to these cell structures, supports the notion that these cells share some of the features of endothelial cells (30). Thus, it appears that endothelial-like cell types and thereby eNOS localisation is not restricted to the intima layer of veins (31).

\section{Conclusions}

Hypophysectomy per se, is associated with decreased BP and HR. Seven days replacement with GH results in increased eNOS expression in the vasculature, normalisation of $\mathrm{HR}$, but has no effect on the reduced BP. Our results suggest that the induction of eNOS expression 
seen in the arteries (aorta) after GH treatment could partly be mediated by IGF-I and/or be a direct effect of $\mathrm{GH}$ on the vascular cells, whereas in the veins (caval vein) a so far unknown indirect effect of $\mathrm{GH}$ may mediate the increased eNOS expression. These findings support the suggested positive role of $\mathrm{GH}$ in the regulation of the cardiovascular homeostasis. The observed up-regulation of eNOS, and presumably an increased NO bioavailability, may result in improved endothelial and cardiovascular function.

\section{Acknowledgements}

This study was supported by the Swedish Medical Research Council (L Hedin; 10375, 12605 and G Bergström; 12580), the Swedish Society for Medical Research (AW), the Swedish National Heart and Lung Foundation (AW, IHJ and GB), and the Foundations of Sannäs (LH), Vårdal (AW) and the Norwegian Health Association (LH).

\section{References}

1 Carroll PV, Christ ER, Bengtsson BA, Carlsson L, Christiansen JS, Clemmons D et al. Growth hormone deficiency in adulthood and the effects of growth hormone replacement: a review. Growth Hormone Research Society Scientific Committee. Journal of Clinical Endocrinology and Metabolism 199883 382-395.

2 Saccá L, Cittadini A \& Fazio S. Growth hormone and the heart. Endocrine Reviews 199415 555-573.

3 Capaldo B, Guardasole V, Pardo F, Matarazzo M, Di Rella F, Numis $\mathrm{F}$ et al. Abnormal vascular reactivity in growth hormone deficiency. Circulation 2001103 520-524.

4 Böger RH, Skamira C, Bode-Böger SM, Brabant G \& von zur Muhlen A. Nitric oxide may mediate the hemodynamic effects of recombinant growth hormone in patients with acquired growth hormone deficiency. Journal of Clinical Investigation 1996 $982706-2713$.

5 Caidahl K, Edén S \& Bengtsson B-Å. Cardiovascular and renal effects of growth hormone. Clinical Endocrinology $1994 \mathbf{4 0}$ 393-400.

6 László FA, Csernay L \& Kocsis J. Effects of hypophysectomy on haemodynamic changes induced by administration of oestrone + vasopressin. Research in Experimental Medicine 1974163 219-227.

7 Shen Y-T, Wiedmann RT, Lynch JJ, Grossman W \& Johnson RG. $\mathrm{GH}$ replacement fails to improve ventricular function in hypophysectomized rats with myocardial infarction. American Journal of Physiology 1996271 H1721-H1727.

8 Folkow B, Isaksson OPG, Karlström G, Lever AF \& Nordlander M. The importance of hypophyseal hormones for structural cardiovascular adaptation in hypertension. Journal of Hypertension 19886 S166-S169.

9 Folkow B, Isaksson OGP, Karlström G, Lever AF \& Nordlander M. Trophic effects of hypophyseal hormones on resistance vessels and the heart in normotensive and renal hypertensive rats. Acta Physiologica Scandinavica $1992144291-306$.

10 Rossoni G, Locatelli V, De GC V, Torsello A, Schweiger F, Boghen M et al. Growth hormone and hexarelin prevent endothelial vasodilator dysfunction in aortic rings of the hypophysectomized rat. Journal of Cardiovascular Pharmacology 1999 34 454-460.

11 Forstermann U, Boissel JP \& Kleinert H. Expressional control of the constitutive isoforms of nitric oxide synthase (NOS I and
NOS III). The Federation of American Societies for Experimental Biology Journal 199812 773-790.

12 Jonsdottir IH, Jungersten L, Johansson C, Wennmalm A., Thorén P \& Hoffmann P. Increase in nitric oxide formation after chronic voluntary exercise in spontaneously hypertensive rats. Acta Physiologica Scandinavica 1998162 149-153.

13 Groesbeck MD \& Parlow AF. Highly improved precision of the hypophysectomized female rat body weight gain bioassay for growth hormone by increased frequency of injections, avoidance of antibody formation, and other simple modifications. Endocrinology $19871202582-2590$.

14 Oscarsson J, Olofsson SO, Bondjers G \& Eden S. Differential effects of continuous versus intermittent administration of growth hormone to hypophysectomized female rats on serum lipoproteins and their apoproteins. Endocrinology 1989125 1638-1649.

15 Oscarsson J, Ottosson M, Vikman-Adolfsson K, Frick F, Enerback $\mathrm{S}$, Lithell H et al. GH but not IGF-I or insulin increases lipoprotein lipase activity in muscle tissues of hypophysectomised rats. Journal of Endocrinology $1999160247-255$.

16 Gustafsson H, Wickman Tordby A, Brandin L, Hedin L \& Jonsdottir IH. The interactive effects of growth hormone and oestrogen on vascular responses in hypophysectomized female rats. European Journal of Endocrinology $20021461-8$.

17 Hedin L, Gaddy-Kurten D, Kurten R, DeWitt DL, Smith WL \& Richards JS. Prostaglandin endoperoxide synthase in rat ovarian follicles: content, cellular distribution, and evidence for hormonal induction preceding ovulation. Endocrinology $1987121722-731$.

18 Rask K, Thorn M, Ponten F, Kraaz W, Sundfeldt K, Hedin L et al. Increased expression of the transcription factors CCAAT-enhancer binding protein-beta (C/EBBeta) and C/EBzeta (CHOP) correlate with invasiveness of human colorectal cancer. International Journal of Cancer $2000 \mathbf{8 6} 337-343$.

19 Piontkewitz Y, Enerback S \& Hedin L. Expression and hormonal regulation of the CCAAT enhancer binding protein-alpha during differentiation of rat ovarian follicles. Endocrinology 1993133 2327-2333.

20 Ooshima A, Fuller GC, Cardinale GJ, Spector S \& Udenfriend S. Reduction of collagen biosynthesis in blood vessels and other tissues by reserpine and hypophysectomy. PNAS $1977 \mathbf{7 4}$ 777-779.

21 Boulanger CM, Heymes C, Benessiano J, Geske RS, Levy BI \& Vanhoutte PM. Neuronal nitric oxide synthase is expressed in rat vascular smooth muscle cells: activation by angiotensin II in hypertension. Circulation Research 199883 1271-1278.

22 Fleming I \& Busse R. Signal transduction of eNOS activation. Cardiovascular Research $199943532-541$.

23 Schini-Kerth VB. Dual effects of insulin-like growth factor-I on the constitutive and inducible nitric oxide (NO) synthase-dependent formation of NO in vascular cells. Journal of Endocrinological Investigation 199922 (Suppl 5) 82-88.

24 Walsh MF, Barazi M, Pete G, Muniyappa R, Dunbar JC \& Sowers JR. Insulin-like growth factor I diminishes in vivo and in vitro vascular contractility: role of vascular nitric oxide. Endocrinology $19961371798-1803$.

25 Jayachandran M, Hayashi T, Sumi D, Thakur NK, Kano H, Ignarro LJ et al. Up-regulation of endothelial nitric oxide synthase through beta (2)-adrenergic receptor-the role of a beta-blocker with NO-releasing action. Biochemical and Biophysical Research Communications 2001 280 589-594.

26 Gan LM, Selin-Sjogren L, Doroudi R \& Jern S. Temporal regulation of endothelial ET-1 and eNOS expression in intact human conduit vessels exposed to different intraluminal pressure levels at physiological shear stress. Cardiovascular Research 200048 168-177.

27 Jorgensen JO, Ovesen P, Juul A, Hansen TK, Skakkebaek NE \& Christiansen JS. Impact of growth hormone administration on other hormonal axes. Hormone Research 199951 (Suppl 3) $121-126$.

28 Geelhoed-Duijvestijn PH, Roelfsema F, Schroder-van der Elst JP, van Doorn J \& van der Heide D. Effect of administration of growth hormone on plasma and intracellular levels of thyroxine 
and tri-iodothyronine in thyroidectomized thyroxine-treated rats. Journal of Endocrinology 1992133 45-49.

29 Fernandez V, Cornejo P, Tapia G \& Videla LA. Influence of hyperthyroidism on the activity of liver nitric oxide synthase in the rat. Nitric Oxide 1997 1 463-468.

30 Sehested M \& Hou-Jensen K. Factor VII related antigen as an endothelial cell marker in benign and malignant diseases. Virchows Archiv. A, Pathological Anatomy and Histopathology 1981391 217-225.
31 Gutterman DD. Adventitia-dependent influences on vascular function. American Journal of Physiology 1999277 H1265$\mathrm{H} 1272$.

Received 9 January 2002

Accepted 3 June 2002 